\title{
Coelomic fluid of Lumbricus rubellus enhances anti-prolioniferative effect of 5-fluorouracil by modulating focal adhesion kinase express and IL-1 $\beta$ of colorectal cancer in mice
}

\author{
Sofy Permana ${ }^{1 *}$, Reny Purnama Hadi ${ }^{2}$, Eviana Norahmawati ${ }^{3}$, Agustina Tri Endharti ${ }^{4,5}$ \\ ${ }^{1}$ Department of Biology, Faculty of Mathematics and Natural Sciences, Brawijaya University, Jawa Timur, Indonesia. \\ ${ }^{2}$ Master Program in Biomedical Science, Faculty of Medicine, Brawijaya University, Jawa Timur, Indonesia. \\ ${ }^{3}$ Department of Pathology Anatomy, Faculty of Medicine, Brawijaya University, Jawa Timur, Indonesia. \\ ${ }^{4}$ Biomedical Central Laboratory, Faculty of Medicine, Brawijaya University, Jawa Timur, Indonesia. \\ ${ }^{5}$ Department of Parasitology, Faculty of Medicine, Brawijaya University, Jawa Timur, Indonesia.
}

\begin{tabular}{l}
\hline ARTICLE INFO \\
\hline Received on: 04/03/2019 \\
Accepted on: 01/06/2019 \\
Available online: 03/08/2019 \\
\hline Key words: \\
Coelomic fluid, colorectal \\
cancer, focal adhesion kinase, \\
IL-1, proliferation.
\end{tabular}

\begin{abstract}
The different malignancy advancing systems related with focal adhesion kinase (FAK) can be attentive in the progression of colorectal cancer. By inhibiting the growth mechanism of mixture of 5-Fluorouracil (5-FU) and earthworm therapy could enhance the affectability of malignant growth cells. The objective of this research was to explore the antiproliferative activity of mixed coelomic fluid cancer medicines produced from Lumbricus rubellus. Colorectal cancer was actuated in mice by injected HT-29 cells in the caecum of mice, and then 5\% dextran sodium sulfate were given by the drinking water. To investigate the effect of combination treatment, we divided of five treatment groups: group 1 was untreated (vehicle), groups $2-5$ were given by 5 -FU. Groups $3-5$ were given by a combination of 5-FU (50 $\mu \mathrm{g} / \mathrm{g} \mathrm{BW})$ and coelomic fluid $(50,100$, and $200 \mu \mathrm{g} / \mathrm{g} \mathrm{BW})$, respectively. The administrated of coelomic fluid was started from the 4 th weeks. Mice were sacrificed at the end of 8 weeks and colon tissue was isolated, then assessed using Flowcytometry and immunofluorescent. These findings revealed that the mixture of 5FU and coelomic fluid components inhibits growth considerably, Interleukin-1 $(\mathrm{IL}-1 \beta)$ and FAK compare with 5-FU only group $(p<0.001 ; p<0.05$; and $p<0.001)$. Treatment used coelomic fluid at a dose of $200 \mu \mathrm{g} / \mathrm{g}$ BW decreased FAK expression. The combination of 5-FU and coelomic fluid at a dose of $200 \mu \mathrm{g} / \mathrm{g} \mathrm{BW}$ decreased the percentage of IL-1 $\beta(p<0.05)$.
\end{abstract}

\section{INTRODUCTION}

Cancer cell was characterized by a physiological change from normal cell that causes differentiation and proliferation into malignant form. Proliferation in cancer cell plays the main roles not only for the growth of cancer cell but also for metastases of the cancer cells (Demetrius et al., 2010). For the survival of cancer cells, they need to proliferate and attached to their environment. The processes of cancer differentiation, proliferation, and metastases

\footnotetext{
${ }^{*}$ Corresponding Author

Sofy Permana, Department of Biology, Faculty of Mathematics and Natural Sciences, Brawijaya University, Jawa Timur, Indonesia. E-mail:sofybioub@gmail.com
}

have been involved of focal adhesion kinase (FAK). The binding of structural characteristics of FAK and several FAK expressions often related to the poor prognoses of the cancer disease (Ling Tai et al., 2015; Sulzmaier et al., 2014). Several types of FAK have already been confirmed in many cancer tissues, including breast, thyroid, ovary, head, and neck and colon (Yoon et al., 2015). FAK is an important mediator between cells and the extracellular matrix and is closely related to the signaling pathway for inflammation. Inflammatory cells comprise a range of mediators, which include growth regulators cytokines, and chemokine, inducing tumor development, invasion, and metastasis. Interleukin-1 $\beta$ (IL-1 $\beta$ ) has been playing roles in tumor growth and metastasis and has been reported to control tumor invasion and carcinogenesis (Mon et al., 
2017). IL-1 $\beta$ activated FAK. FAK is required for IL-1 $\beta$-induced cell invasion.

Chemotherapy drugs, such as 5-fluorouracil (5-FU), already known to cure colorectal cancer. 5-FU has a mechanism to inhibit the activation of thymidylate synthase and DNA repair in cancer cells. This chemotherapy drug was known able to increase the live rate of the cancer patients (Wei et al., 2016). Although already known being successful as a cancer therapy, 5-FU has known many side effects and multi-drug resistance on cancer patients, such as nausea, vomit, loss of appetite, alopecia, and neurologic disorder (Thomas et al., 2016).

Today, earthworms have many opportunities in medical research because of their components that can function as immunoprotective molecules. These molecules showed different activities, such as fibrinolytic, anticoagulative, anticancer, antimicrobial, and thus may be exploited for the treatment of various diseases. Lumbricus rubellus is one of an earthworm species that has potential as anti-inflammatory, anti-oxidant, anti-bacterial, anti-fibrinolysis, and anti-tumor with lysenin as its bioactive compound (Parwanto et al., 2016). Lysenin in Eisenia fetida showed its ability to significantly inhibit the growth of mammary cancer (Vidya et al., 2016). Our recent study also showed the ability of coelomic fluid to inhibit the proliferation of colorectal cancer in vitro (Endharti et al., 2018a). This study was aimed to investigate the potential therapy of coelomic fluid to inhibit proliferation and metastasis by signaling of IL- $1 \beta$ to regulate cell migration and invasion. However, the antitumor activity and coelomic fluid molecular functions in colon cancer have not yet been established.

\section{MATERIAL AND METHODS}

\section{Mice}

Female Balb/c mice (8-10 weeks) were purchased from Pusvetma Surabaya. Mice were kept in a $25^{\circ} \mathrm{C}-27^{\circ} \mathrm{C}$ warmth, comparative humidity $(55 \pm 5 \%)$ and 12 hours/12 hours light/ dark cycles under normal circumstances. During the experimental cycles, mice received ordinary drinking water ad libitum. All the studies were carried out in accordance with the guidelines of Animals for Scientific Purpose in The Institutional Animal Care and Use Committee (IAUCUC) and authorized by the University of Brawijaya, Malang, Indonesia Ethical Committee (No. 937-KEP-UB).

\section{Coelomic fluid collection}

Lumbricus rubellus were obtained from CV Rumah Alam Jaya Organik, Sukun, Malang. The earthworms were place in box which already filled with organic matter. In order to remove adhering materials or particles, earthworms $(30 \mathrm{~g})$ were rinsed with distilled water and then blotted dry using tissue paper. The coelomic liquid was gathered by warmth and cold treatment as indicated by technique which was clarified by Endharti et al (2018a). Earthworms were suspended in phosphate buffered saline $(\mathrm{PBS})(10 \mathrm{ml})$ and subjected to temperature of $50^{\circ} \mathrm{C}$, and 5-minute interval cycling (six-eight times). Due to cold and hot shock treatments were synthesized and collected into tubes and stored in aliquots at $-20^{\circ} \mathrm{C}$.

\section{Maintenance and culture of HT-29 cells}

This exploration utilized human colorectal malignant growth cell line (HT-29) which was bought from American Type Culture Collection (ATCC ${ }^{\circledR}$ HTB38 ${ }^{\mathrm{TM}}$, USA). With $1 \%$ penicillin-streptomycin, 10\% fetal bovine serum (FBS) and 1\% amphotericin, cells were retained in the medium of McCoy. In the humidified $\mathrm{CO} 2$ incubator, cells were cultivated (Binder's, USA) at $5 \% \mathrm{CO}_{2}$ at $37^{\circ} \mathrm{C}$.

\section{Induction of colon cancer}

Colorectal cancer animal model was done according to Endharti et al (2016) and Takahashi et al (2004) by modification. The mice received 3\% dextran sodium sulfate (DSS) of drinking water (ICN Biomedical Inc, CA). Colon cancer was induced in mice by intra-rectal injection of $2 \times 10^{6}$ HT-29 cells/mouse according to Yi et al (2013). A occult blood detection device has been used to observe the progression of colitis daily (Hemoccult). The mice were sacrificed at the end of 8 weeks. According to Endharti et al. (2017a and 2017b), the administration of coelomic fluid (CL) started at 4 weeks until 8 weeks.

\section{The effect of CL combination therapy in vivo}

To identify the therapeutic effect of 5FU and CL combination therapy, mice were randomly divided into five groups. Group 1 was given water (vehicle). Groups 2-6 were given 3\% DSS and HT-29 cells. Groups 3-5 were treated 5-FU $(50 \mu \mathrm{g} / \mathrm{g}$ BW). Groups 4-6 were received CL at 50, 100, or $200 \mu \mathrm{g} / \mathrm{g} \mathrm{BW}$, respectively. Group 7 was given CF only $(200 \mu \mathrm{g} / \mathrm{g} \mathrm{BW})$. Four weeks after injecting with HT-29 cells, the mice of groups 3-7 were intra-peritoneally injected with CL every week. Mice were sacrificed at the end of 8 weeks, in all the groups. Colon tissue was separated and washed and then analyzed for flow cytometry and immunofluorescent.

\section{Isolation of mouse colon epithelial cells}

The culture medium used was enhanced by RPMI 1640 (Gibco) with 10\% FBS, $20 \mathrm{mM}$ Hepes, $4 \mathrm{mM}$ glutamine, U/ml 100 penicillin, U/ml 100 streptomycin (Sigma) by Endharti et al. (2018a).

Briefly, cells of the colon were sliced into parts of 1 $\mathrm{mm}$. In the presence of $200 \mathrm{U} / \mathrm{ml}$ type I collagenase (Sigma), 2 $\mathrm{mM}$ ethylenediaminetetraacetic acid and $25 \mathrm{mM}$ Tris (Sigma), the tissue fragments were incubated at $37 \mathrm{C}$ in Hanks' Balanced Salt Solution Hanks' Balanced Salt Solution (Sigma). The fragments of the tissue were resuspended and centrifuged for 5 minutes at $4 \mathrm{C}$ at $1,200 \mathrm{rpm}$. The supernatant containing the purified epithelial cells were collected by centrifugation at $1,200 \mathrm{rpm}$ at $4{ }^{\circ} \mathrm{C}$ then separated by Percoll (Sigma) density gradient.

\section{Flow cytometry and intracellular staining}

For intracellular cytokine measurement, mesenteric lymph nodes (MLNs) cells were stimulated for 5 hours with PMA (1 $\mu \mathrm{g} / \mathrm{ml}$, Sigma Aldrich) and ionomycin $(50 \mu \mathrm{g} / \mathrm{ml}, \mathrm{BD}$ Biosciences $)$ in the presence of monensin $(0.1 \mathrm{mg} / \mathrm{ml}$, Sigma Aldrich) and placed in a $37^{\circ} \mathrm{C}$ and $5 \% \mathrm{CO}_{2}$. MLN cells were fixed and permeabilized (Cytofix/Cytoperm, BD Biosciences) and stained intracellular with anti-IL-1 $\beta$-FITC (Biolegend, Uithoorn, 
Netherlands). The stained cells were analyzed using FACS Calibur, and the data were analyzed using Cell Quest Pro software.

\section{Immunofluorescence staining}

Colon tissue was then sectioned into paraffin about 6 $\mu \mathrm{m}$. The tissues were then deparaffinized and hydrate. Then, the tissue incubated in buffer citrate for 20 minutes water bath for antigen retrieval followed by $3 \%$ bovine serum albumin incubation at room temperature for 30 minutes. The tissue was blocked and incubated with the following primary antibody at $37 \mathrm{C}$ for 2 hours: FAK, Santa Cruz Biotechnology, Inc., USA (1:100) The tissue was then incubated with the secondary antibodies goat antimouse FITC for 1 hour at room temperature (1:100) for 60 minutes. Cells nuclei were counterstained using 4',6-diamidino-2-phenylendole (DAPI, BioLegend, USA). The sections were observed under Fluorescence microscope (OLYMPUS 1X71). Fluorescence quantifications were analyzed using FIJI/ImageJ 2 software.

\section{Colon epithelial cell proliferation assay}

The cell growth was evaluated with BrdU supplemented by an anti-BrdU-conjugated FITC and Propidium Iodide staining label. Briefly, the epithelial cells were seeded in 24-well tissue growing plates $\left(1 \times 10^{6}\right.$ cells/well $)$, then allowed to settle for 24 hours, maintained at $37^{\circ} \mathrm{C}$ in $5 \% \mathrm{CO}_{2}$ and $95 \%$ humidity and changed with $1 \mathrm{ml}$ of $5 \mu \mathrm{mol} \mathrm{BrdU}$ in medium. After incubation, epithelial cells were cleaned with PBS, collected by $0.25 \%$ trypsin, and solved for 40 minutes in ice cold $70 \%$ ethanol. The cells at $37 \mathrm{C}$ in $1 \mathrm{ml} 2 \mathrm{M} \mathrm{HCl}$ were centrifuged and re-suspended nuclei for 30 minutes.

The epithelial cells were cultured for 10 minutes at room temperature in $2 \mathrm{ml} 0.1 \mathrm{M}$ potassium tetraborate $(\mathrm{pH}=$ 8.5). Cells were then permeabilized at room temperature by $0.1 \%$ Tween-20-1\% BSA in PBS for 5 minutes, supplemented by anti-BrdU mouse staining. (Biolegend, Cat. No: 339801) in PBS and Nuclear DNA $20 \mu \mathrm{g} / \mathrm{ml}$ of propidium iodide has been stained (PI, Sigma) at room temperature for 30 minutes. Finally, a BD FACS Calibur fluid cytometer was used to analyze the epithelial cells (Becton Dickinson, San Jose, CA).

\section{Statistical analysis}

A one-way ANOVA was used to analyze all the data. The data outcome was defined as a mean \pm standard deviation and the statistical significance of a distinction regarded significant with $\mathrm{p}$ $<0.05$ between each group. The statistical assessment was carried out using the statistical software SPSS 16 (SPSS Inc, USA).

\section{RESULT AND DISCUSSION}

\section{5-FU and coelomic fluid combine to prevent cell growth}

In this study, epithelial cells proliferation in the colon tissue was observed by using Ki67 staining performed by flow cytometry. In HT29-DSSonly group, the epithelial cells of colon mice were proliferated. The combination therapy of 5-FU and CL groups able to inhibited proliferation compared to the single therapy group. The spread of colonic epithelial cells in HT29DSS-induced colorectal disease was considerably greater than the mixture of 5-FU and CL therapy groups $(p<0.05)$ (Fig. 1A and $\mathrm{B}$ ). The treatment of CL-combined therapy could reduce the proliferation of epithelial cells which demonstrated by percentages of Ki-67 in colon tissue.

This result also showed that the combination of 5-FU and various concentrations of $\mathrm{CL}(50,100$, and $200 \mu \mathrm{g} / \mathrm{g} \mathrm{BW})$ significantly reduced cancer proliferation $(p<0.05 ; p<0.05$; and $p<0.001)$. This finding provided that the combined therapy synergistically abolished carcinogenesis in the model of colorectal cancer by suppressing growth and development mechanism.

\section{The combination effect of 5-FU and coelomic fluid reduce FAK expression}

To further investigate the anti-cancer effect of CL combination therapy, we assessed the expression of FAK. We analyzed the expression of FAK on the colon tissue of mice used direct immunofluorescence. The image showed the expression of FAK was reduced with 5-FU and various concentrations of CL (50, 100, and $200 \mu \mathrm{g} / \mathrm{g} \mathrm{BW}$ ) (Fig. 3A) When the combination of CL and 5-FU were applied, FAK expression was lower than 5-FU or CFL alone $(p<0.05)$, which indicated that FAK expression was decreased via $\mathrm{CFL}$ and 5-FU combinations (Fig. 2A and B). The highest
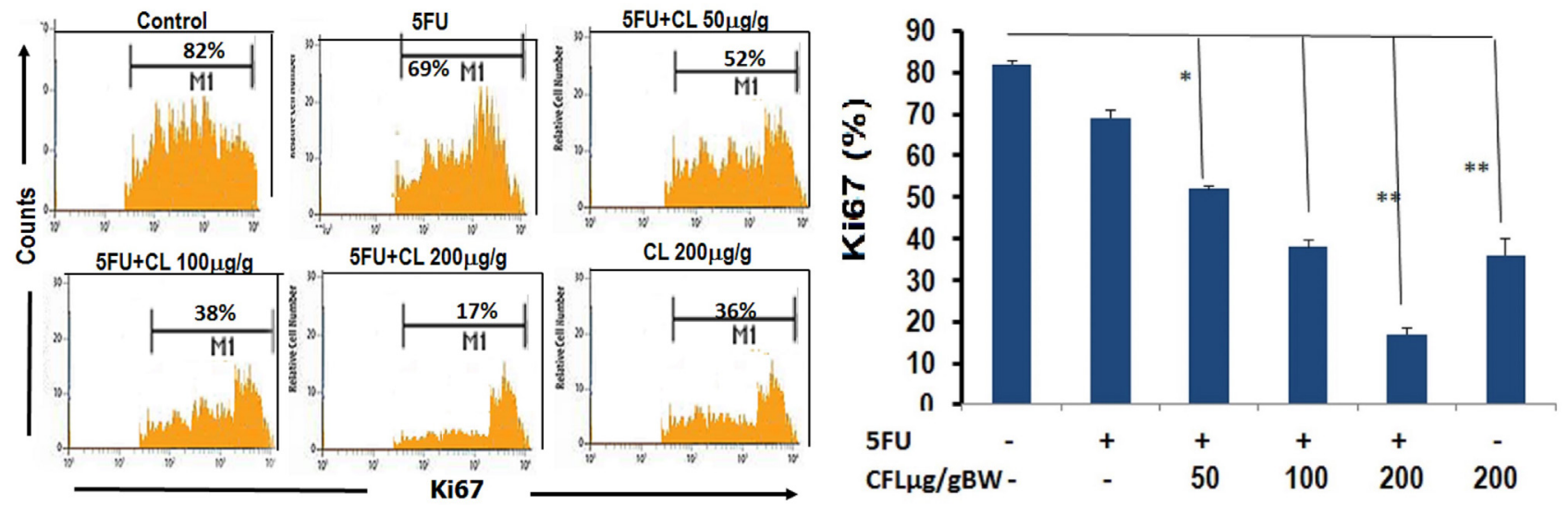

Figure 1. The expression of cell proliferation was inhibited by 5-FU and CL in colon tissue. (A) The expressions of proliferation were analyzed using immunofluorescence. Representative result from each group inhibited proliferation in CL combination groups. (B) Number positive cells indicated cell proliferation (results shown are mean $\pm \mathrm{SD}$, with $n=4$ ). Number of proliferation cells showed that Combination therapy groups have lower number cell proliferation than single therapy group. Results shown were mean \pm SD with $n=4$ replicated in each group by $* p<0.05, * * p<0.001$. 
concentration of the combination therapy group demonstrated the decreasing of FAK expression until $68 \%$. The combined impact of 5-FU and coelomic fluid decreases the amount of IL-1 $\beta$ cells. We assessed the effect of 5-FU and CL combination therapy on the presentation of IL- $1 \beta$ cells. Treatment with CL combination therapy suppressed significantly decreased the presentation of IL-1 $\beta$ cells (Fig. 3A and B). Taken together, these results indicate that the CL combination therapy able to reduce the number of IL-1 $\beta$ cells in HT29-DSS induced colon cancer.

Colorectal cancer is a major cause of morbidity and mortality throughout the world. It is the third most common cancer worldwide and the fourth most common cause of death (Roper and Hung, 2013). Colorectal cancer is formed by adenomatous neoplasm which have ability to undergo into malignant form depend on their environment (Mundade et al., 2014). The main cause of cancer morbidity is the distribution of cancer cells from the main tumor to nearby tissues and detached bodies. High and uncontrolled invading and spreading was known to have correlation on physiological change of cancer. Progression changes the benign tumor into a malignant tumor (Hyland, 2010). Many factors which cause of high proliferation in the cancer cell, such as unbalance of proto-oncogene and tumor suppressor gene. The increasing of proliferation which was identified by one of its marker, such as $\mathrm{Ki}-67$, reported being correlated with the outcome of the cancer, and gives a poor prognosis in cancer patient (Melling et al., 2015). Our result demonstrated that the combination treatment of 5-FU and CL on the dose $200 \mu \mathrm{g} / \mathrm{gBW}$. This is consistent with what has been found in previous study that coelomic fluid able to suppress proliferation and enhance apoptosis of HT-29 cells was investigated in vitro (Endharti et al., 2018a; Permana et al., 2018).

In the present research, we aimed to explore the antimetastatic effect of CF combination treatment. FAK is one of the molecules used to regulate signal transduction, cell permeability, and development. In cancer cell, the expression of FAK will increase and give advantages for the cancer cell to grow and metastases (Yoon et al., 2015). The highest concentration of this combination significantly reduced proliferation and FAK expressions than a single therapy of 5-FU or CL. Figures $1 \mathrm{~B}$ and
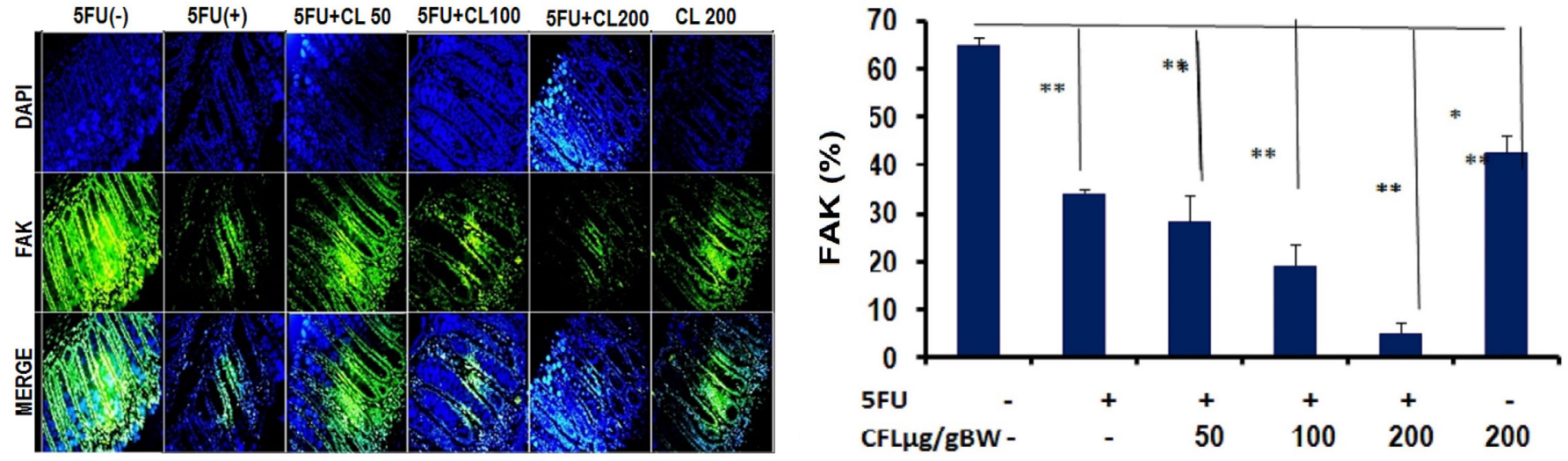

Figure 2. FAK expressions were reduced of 5-FU and CL in colon tissue. The expression of FAK post therapies with 5-FU and various concentration of CL (50, 100 , and $200 \mu \mathrm{g} / \mathrm{g} \mathrm{BW}$ ) were analyzed using direct immunofluorescence. (A) The expression of FAK reduced in colon tissue by the decreasing of fluorescence intensity. Representative images of FAK expression showed a slightly lower on the combination therapy group. (B) The percentage of FAK expression decrease on combination therapy groups compare with single group. Results shown are mean $\pm \mathrm{SD}$, with $n=4$ replicates in each group. ${ }^{*} p<0.05, * * p<0.001$.
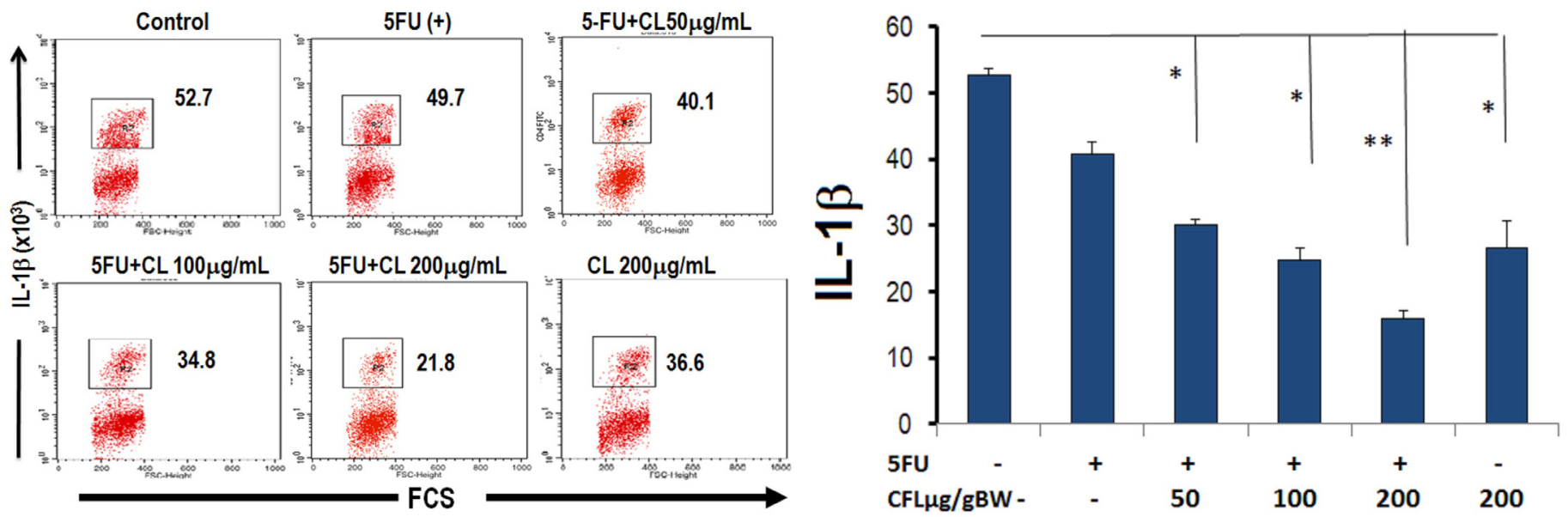

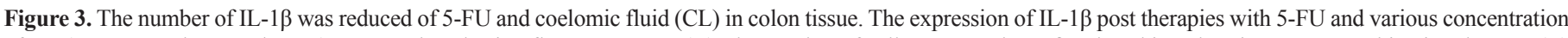

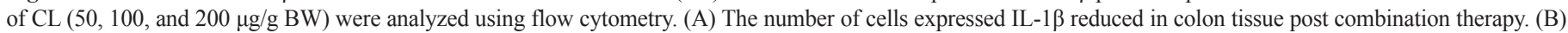

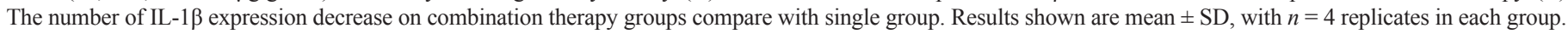
$* p<0.05, * * p<0.001$. 
2B showed that the combination therapy of 5-FU and various concentrations of CL able to inhibit proliferation as well as reduce FAK expression. FAK is activated by integrin and growth factor and involve kinase-dependent control of motility, invasion, also survival from the cancer cell. The activation of FAK is important for cancer cell adhesion, lead to increase proliferation and survival of cancer cell. This activation also facilitated cancer cell to migration and metastases on other tissue (Sulzmaier et al., 2014).

5-FU has already been identified as a chemotherapy for the treatment of cancer cells with one or more antineoplastic cytotoxic agents. In this result, demonstrated the combination of of 5-FU and CL resulted in a synergistic antitumor effect by enhancing drug ability as anti-proliferative. On recent in vitro study of earthworm's coelomic fluid, it is known that the active compound of coelomic fluid able to inhibit the growth of cancer cell line (Vidya et al., 2016). IL1 $\beta$ regulates the invasion of cancer cells by enhancing MMP9 development through FAK (Jeong et al., 2018). The coelomic fluid compound, such as lysenin, already being known has potential as cancer therapy by specifically bind with the sphingomyelin of cancer cell. Lysenin forms oligomers in a sphingomyelin dependent way after binding to the cell membranes of the target cells. Biochemical reactions in cell membranes between lysenin and sphingomyelin are essential for lysenin's pharmacological functions, such as cytotoxicity (Collibus et al., 2012). Lysenin will bind with FcyRIIA receptor in the surface of the cell then break down the sphingomyelin into ceramide. Ceramide is one of sphingolipid which also known as a lipid mediator and have function to induce apoptosis, differentiation, migration, and reduce adhesion molecule in cancer (Morad et al., 2016; Taniguchi and Okazaki, 2013;). These data strong suggested that treatment with a single agent or a combination of CL able to diminish FAK expression in dose-dependent manner for each group (Fig. 3A and B).

In this research, coelomic fluid of Lumbricus rubellus and 5-FU synergistically inhibit cancer proliferation. 5-FU metabolite substance might disturb DNA and RNA synthesis and repair on the cancer cell, which also leads to decrease mobility and activity of the integrin (Muhale et al., 2011; Endhartiet al., 2018b; $2018 \mathrm{c}$ ). This is maybe also going to cause the disturbance of adhesion molecule activity inside of cancer cell, so it will inhibit cell proliferation. In the other hand, the ability of coelomic fluid to bind integrin will cause the destruction of integrin which also lead the decreasing of FAK expression (Morad et al., 2016).

Our research verified that $\mathrm{CL}$ treatment with single or mixture therapy is capable of inhibiting colorectal cancer growth in vitro by decreasing FAK expression. In this study, we demonstrated that the combination of 5-FU and coleomic fluid from Lumbricus rubellus able to inhibit proliferation in colorectal cancer in vivo by FAK expression in colon tissue. A mixture of chosen natural compounds has been shown to improve the effectiveness of chemotherapy therapy and increase the tolerance of the medication in cancer. This data indicated that CL has potential to use as a purpose to minimize the dose of 5-FU and reduce the resistance of chemotherapy drugs. Targeting FAK inhibition can be used as a new cancer-resistant preventive and therapy approach.
This research also able to show that proliferation mediated FAK expression was involved in the reduction of IL-1 $\beta$. Our findings show that the strong chemical-sensitive impact of CL in our chemoresistant is inhibited by FAK, leading then to IL-1 $\beta$ down regulation. The results of the current study show that FAK is activated by IL- $1 \beta$ and plays a critical role in the invasion of tumor cells.

\section{CONCLUSION}

In conclusion, this study showed that the combination of the 5-FU and $\mathrm{CL}$ able to inhibit proliferation by reducing FAK expression in colorectal cancer in vivo. This finding maybe offers a promising method for a new anticancer therapy concept, especially for colorectal cancer treatment.

\section{ACKNOWLEDGMENTS}

We would like to offer the greatest appreciation to the Directorate General for Higher Education, the Ministry of National Education and Culture, Indonesia, who granted us funding for this studies. We are also grateful for this Heni Endarwati, S.Si, Bunga Prihardina, S.Si, Ami Maghfironi, S.Si, Wahyudha Ngatiril Lady, S.Si, and Suci Megasari, S.Si., MP for the technical assistance during this research.

\section{CONFLICT OF INTEREST}

The authors declare that there is no conflict of interest regarding the publication of this paper.

\section{REFERENCES}

Collibus LD, Sonnen AFP, Morris KJ, Siebert CA, Abrusci P. Structure of lysenin reveal a shared evolutionary origin for pore-forming proteins and its mode of sphingomyelin recognition. Structure, 2012; 20:1498-507.

Demetrius LA, Coy JF, Tuszynski JA. Cancer proliferation and therapy: the Warburg effect and quantum metabolism. Theor Biol Med Model, 2010; 19:7:2

Endharti AT, Baskoro AD, Norahmawati. E. Therapeutic effect of soluble worm protein acting as immune regulatory on colitis. Asian Pac J Trop Biomed, 2017a; 7(1):70-7.

Endharti AT, Permana S. Extract from mango mistletoes Dendrophthoepentandra ameliorates TNBS induced colitis by regulating CD4+ T cells in mesenteric lymph nodes. BMC Complement Altern Med, 2017b; 17:468

Endharti AT, Permana S. T-Bet is dependent on Stat4 inhibiting acute colitis but not Stat-1 using L4 somatic antigen of heligmosomoidespolygyrus. Sci World J, 2018a; 2018:1-9.

Endharti AT, Sulastri E, Umanailo R, Yunialce, Nurseta T. Mango mistletoe Dendrophthoepentandra leaf extract acts synergistically with 5-Fluorouracil to induce apoptosis and increase p21 expression in human cervical adenocarcinoma HeLa cells by reducing survivin expression. J Appl Pharma Sci, 2018c; 8(07):010-5.

Endharti AT, Wahyuningtyas TE, Hardini, Handono K, Widjajanto E. Dendrophthoepentandra leaves extract promotes apoptotic effects of doxorubicin in human breast cancer cell via modulation of intracellular calcium and survivin. J Appl Pharma Sci, 2018b; 8(08):039-46.

Endharti AT, Wulandari A, Listyana A. Dendrophthoepentandra (L.) Miq extract effectively inhibits inflammation, proliferation and induces p53 expression on colitis-associated colon cancer. BMC Complement Altern Med, 2016; 16(1):374-88.

Hyland K. Cell proliferation and its regulation. Biochemistry/ molecular biology lecture. In: Albert (ed.). Molecular biology of the cell. 5th edition, Garland Science, New York, NY, pp 1230-1256, 2010, Chapter 20: Cancer. 
Jeong KY. Inhibiting focal adhesion kinase: a potential target for enhancing therapeutic efficacy in colorectal cancer therapy. World J Gastrointest Oncol, 2018; 15(10):290-2.

Ling Tai, Y., Chen LC, Shen TL. Emerging roles of focal adhesiom kinase in cancer. Biomed Res Int, 2015; 2015:1-14.

Melling N, Kowitz CM, Simon R, Bokemeyer C, Terracciano L. High Ki67 expression is an independent good prognostic marker in colorectal cancer. J Clin Pathol, 2015; 1:1-6.

Mon NN, Senga T, Ito S. Interleukin- $1 \beta$ activates focal adhesion kinase and Src to induce matrix metalloproteinase- 9 production and invasion of MCF-7 breast cancer cells. Oncol Lett, 2017; 13(2):955-60.

Morad SAF, Bridges ADA, Larrea AL, Mayen MR, MacDougall T. Short-chain ceramides depress integrin cell surface expression and function in colorectal cancer cells. Cancer Lett, 2016; 03:049.

Muhale FA, Wetmore BA, Thomas RS, McLeod HL. System pharmacology assessment of 5-Flourouracil pathway. Pharmacogenomics, 2011; 12(3):341-50.

Mundade R, Imperiale TF, Prabhu L, Loehrer PJ, Lou T. Genetic pathways, prevention, and treatment of sporadic colorectal cancer. Oncoscience, 2014; 1(6):400-6.

Parwanto MLE, Mahyunis, Senjaya H, Edy HJ. Syamsurizal fractionation and characterization of proteins in Lumbricus rubellus powders. Int J Pharma Clin Res, 2016; 8(1):15-21.

Permana S, Pearlindah, Sholihah Z, Iskandar A, Susanti H. Cytotoxic effect and anti-proliferative cancer activity of coelomic fluid from Lumbricus rubellus promotes apotosis and reduce $\mathrm{G} 2 / \mathrm{M}$ phase progression in HT-29 cells. J Appl Pharm Sci, 2018; 8(11):028-34.

Roper J, Hung KE. Molecular mechanism of colorectal cancer. Molecular pathogenesis of colorectal cancer. Springer Science and Business Media, New York, 2013.

Sulzmaier, FJ, Jean C, Schlaepfer DD. FAK in cancer: mechanistic finding and clinical applications. Nat Rev Cancer, 2014; 14(9):598-610.

Takahashi N, Iwasa S, Taniguchi H, Sasaki Y, Shoji H, Honma Y. Prognostic role of ERBB2, MET and VEGFA expression in metastatic colorectal cancer patients treated with anti-EGFR antibodies. Br J Cancer, 2016; 26; 114(9):1003-11.
Taniguchi M, Okazaki T. The role of spingomyelin and spingomyelin synthase in cell death, proliferation, and migration-from cell and animal models to human disorders. Biochim Biophys Acta, 2013; 1841(5):692-703.

Thomas SA, Grami Z, Mehta S, Patel K. Adverse effects of 5-Flourouracil: focus on rare side effects. Cancer Cell Microenviron, 2016; 3:e1266

Tulotta C, Ottewell P. The role of IL-1B in breast cancer bone metastasis. Endocr Relat Cancer, 2018; 25(7): R 421-34.Vidya N, Dinesh MS, Ananda S, Kale RD. Cytotoxic potential of Eudrilus eugeniae coelomcyte culture supernatant against tumor cells. Int J Sci Res, 2016; $6: 202-5$.

Wei X, Wang W, Wang L, Zhang Y, Chen M. MicroRNA-21 Induces 5-Fluorouracil resistance in human pancreatic cancer cells by regulating PTEN and PDCD4. Cancer Med, 2016; 5(4):693-702.

Yi OR, Seung U, Kim, Park MA, Lee HR, Kang NH. Suppression of the growth of human colorectal cancer cells by therapeutic stem cells expressing cytosine deaminase and interferon-b via their tumor-tropic effect in cellular and xenograft mouse models. Mol Oncol, 2013; 7:543-54.

Yoon H, Dehart JP, Murphy JM, Lim SS. Understanding the roles of FAK in cancer: inhibitors, genetic models, and new insight. J Histochem Cytochem, 2015; 63(2):114-28.

How to cite this article:

Permana S, Hadi RP, Norahmawati E, Endharti AT. Coelomic fluid of Lumbricus rubellus enhances anti-prolioniferative effect of 5-fluorouracil by modulating focal adhesion kinase express and IL-1 $\beta$ of colorectal cancer in mice. J Appl Pharm Sci, 2019; 9(08):041-046. 